\title{
Entrepreneurial Orientation and Firm Performance in the Context of Upper Echelon Theory
}

\author{
Gali, Nazha ${ }^{a}$; Hughes, Mathew ${ }^{a}$; Mallet, Oliver ${ }^{\text {; }}$ Karam, Arze ${ }^{c}$ \\ ${ }^{a}$ Department of Management Entrepreneurship, Durham University, United Kingdom, \\ ${ }^{\mathrm{b}}$ Department of Management, Newcastle University, United Kingdom, ${ }^{\mathrm{c}}$ Department of \\ Economics and Finance, Durham University, United Kingdom
}

\begin{abstract}
Entrepreneurial Orientation (EO) is a firm-level phenomenon, which involves the firm's prospects to take risks, be proactive, and be innovative. Most of the research assumes a positive EO-performance relationship adopting the EO-as-advantage perspective without providing enough theoretical foundations of the way EO enhances performance. This paper provides insights into the EO and firm performance relationship looking into the EO-as-experimentation perspective. Through EO-as-experimentation perspective, we argue for the importance of looking into the differential effects of each of the EO dimensions on firm performance in active and inactive firms. We hypothesized that the effect of each of the proactiveness and innovativeness dimension of EO on firm performance is positive among active firms and negative among inactive firms. Whereas risk taking dimension of EO is negative among active and inactive firms. Based on the results of firm fixed effect regression some empirical support for the hypotheses is presented and discussed.
\end{abstract}

Keywords: EO; risk taking; innovativeness; proactiveness; firm performance; EO-as-experimentation. 